Military Technical College

Kobry El-Kobba

Cairo, Egypt

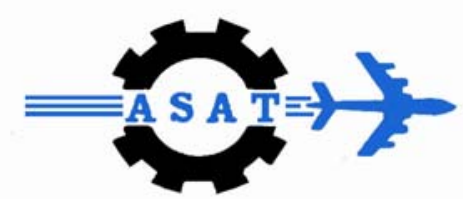

12-th International Conference on

Aerospace Sciences \& Aviation Technology

\title{
DYNAMIC ANALYSIS OF AN ADHESIVE BONDED JOINT FOR COMPOSITE STRUCTURES
}

\author{
Hamada $^{*}$ A. A., Ghoneam ${ }^{* *}$ S. M. and EL-Elamy ${ }^{* * *}$ M. I.
}

\begin{abstract}
This paper introduces an attempt to study the dynamic analysis for laminated composite beam with bonded joints to investigate mainly the influences of lamina code number, bonded adhesive line configuration and boundary condition on the dynamic behavior of composite assembly. The mathematical finite element model (F.E.M.) by introducing unified mechanical parameters is represented to compute efficiently the eigen-nature for composite bonded structures. The experimental analysis is carried out using two techniques. The first includes ultrasonic technique which applies the magnetostractive pulse echo delay-line for material characterization of composite material, while the second includes frequency response function using hammering method. The comparison between experimental and numerical model shows the efficiency of the proposed mathematical model of the composite structural beam with bonded joints. The results show that the changes of the eigen parameters provide a proper indicator for predicting the current state of adhesive bonded joint.
\end{abstract}

Key wards: Adhesive-Bonded joints; Finite element; Damping ; Composite.

\section{Nomenclature}

[K] Stiffness matrix.

[B] Strain matrix.

[D] Elasticity matrix.

[M] Mass matrix.

[N] Matrix of the shape function. Attenuation factor.

$C_{p}$ Phase velocity. $E_{d}$ Dynamic Young's modulus. $L$ Length of specimens.

$\checkmark$ Poisson's ratio $\quad \mathrm{V}, \mathrm{S}, \mathrm{W}$ Bond line configurations

\section{1- INTRODUCTION}

Adhesive-bonded joints have many advantages in terms of stress distribution, design flexibility, and simplicity of fabrication. Structural adhesives are engineering materials, and the adhesive bonding process is a recognized part of production engineering.

\footnotetext{
* Assistant Professor, Dept. of Production Engineering and Mechanical Design, Faculty of Engineering, Menoufiya University, Shebin El-Kom, EGYPT

** Professor, Dept. of Production Engineering and Mechanical Design,

*** Graduate Student, Dept. of Production Engineering and Mechanical Design,
} 
However, as with other fastening methods, adhesive bonding, or more popularly, "chemical welding", has its advantages and limitations which must be considered by modern industrial designers and engineers when choosing between nailing, bolting, riveting, brazing, welding, or bonding to fasten parts together, presented by Kaya A. and et al [1].

He and Rao [2] developed an analytical model to study the coupled transverse and longitudinal vibration of a bonded lap joint system. The system consisted of a pair of parallel and identical beams which were lap-jointed over a certain length by a viscoelastic material. The governing equations of motion for the forced vibration of the system under transverse distributed loads were derived using the energy method and Hamilton's principle.

The theoretical development of the model was presented and then numerical solutions of the governing equations for free vibration along with boundary and continuity conditions yielded the system natural frequencies, loss factors, and mode shapes. However the model is limited to an analytical method without any experimental verification

A mathematical model to study the longitudinal vibration of an adhesively bonded double-strap joint was presented by He and Rao [3]. Hamilton's principle was used to derive the governing equations of motion and the natural boundary conditions of the joint system. The adhesive was modeled as a viscoelastic material using a complex modulus approach. The equations to predict the system resonance frequencies and loss factors were derived from the system natural and forced boundary conditions for the case of simply supported boundary conditions. A special searching strategy for finding the zeros of a complex determinant had been utilized, obtaining the numerical results. The effects of the adhesive shear modulus and structural parameters such as lap ratio and adhesive and strap thicknesses on the system resonance frequencies and loss factors, were also studied by Roy and Reddy [4].

Khalil and Kagho [5] reported nondestructive test of adhesively bonded joints using vibrational analysis. In this study, two types of artificial defect, voids and disbounds, were manufactured. Both types of defect made at different positions and have different sizes. These results indicated that both voids and disbounds could be detected by the reduction in the resonant frequencies and the increase in damping. However, it was difficult to locate the position of the defect and estimate its size.

Kaya [6] investigated stress distributions in adhesive bonded lap joints, single and double, under tension force by a finite element procedure. Distribution stress was plotted in nondimensional coordinates. Also the author found out the effects of the parameters on the stress distribution. The thickness of the adhesive layer was firstly taken into consideration in the model, and secondly, its thickness was ignored for similar and dissimilar adherends. This was a static model and it formed the basis of the present dynamic model. However Kaya model is limited to the static state without regard the dynamic influences.

Shi and Cheng [7] considered the stress distribution in adhesive-bonded cylindrical lap joints subjected to axial loads. They assumed that the two adherents may have arbitrary thicknesses and made from different materials and the adhesive layer may be flexible or inflexible.

In another paper Rao and Zhou [8], a mathematical model was presented the transverse vibration and damping of an adhesively bonded tubular lap joint. The governing equations of motion of the system for the case of forced vibration were first derived by using the energy method and Hamilton's principle. It was assumed that 
the energy dissipated by the joint system was contributed by both the shear and bending deformation of the adhesive layer. By using the finite difference method, the numerical solutions of the governing equations for free vibration under fixed-fixed boundary conditions were obtained. The effects of structural parameters and material properties of the adhesive layer on the system model loss factors and resonance frequencies were also studied by Shin and et al [9], Vaziri and et al [10].

In the present work, various specimens of laminated composite beam made of fiberglass are investigated. Each specimen was made of five plies for various bond line configurations for various code numbers via different boundary conditions within the overture frequency spectrum.

The mathematical finite element models (F. E. M.) are developed to compute the eigen-nature for composite bonded structures. Modified mechanical parameters are introduced to raze the accuracy of developed model.

The experimental analyses are investigated by using two techniques. The first includes the frequency response function using hammering method. The second includes ultrasonic technique in which the magnetosteictive pulse echo delay-line is applies for material characterization of composite material.

The results show that the changes of the eigen parameters provide a proper indicator for predicting the current state of adhesive bonded joint.

\section{2- MATERIALS}

Glass fiber is used as reinforcement in the form of bidirectional fabric (Standard EGlass Fiberglass) and polyester with catalyst addition as matrix for the composite material. The adhesive bond material is Araldite 2015 (AV5308 / HV 5309-1) that is two component epoxy paste adhesive. The mechanical properties of the composite are calculated analytically using the mixture rule [11].

\section{3- PRODUCTION OF THE LAMINATES SPECIMENS}

Through hand lay-up process followed by a cure process under pressure, five sets of symmetrical laminates with a total of five layers each one are produced:

Set1: [0/0/0/0/0], Set2: [0/30/0/30/0], Set3: [0/45/0/45/0]

Set4: [0/60/0/60/0] and Set5: [0/90/0/90/0]. The numbers mentional in the above sets indicates the angle of fiber inclination by degrees.

After the cure process, the laminated beam dimensions with length of $350 \mathrm{~mm}$, width of $40 \mathrm{~mm}$, thickness of $5 \mathrm{~mm}$ and average mass specimen equal to $87 \times 10^{-3}$ $\mathrm{Kg}$.

\section{4- BONDED JOINT CONFIGURATION}

The bonded joint configurations shown in Figure (1) are bond line patterns which consist of cutting known shapes onto the specimens. All of the bond line patterns divide the composite specimens into separated sections. The preparation and manufacturing of specimens are achieved by following the standard procedures. The shapes cut into the specimens are in the forms of $\mathrm{V}, \mathrm{S}$ and $\mathrm{W}$ joints. All of these contours are performed in a $50 \mathrm{~mm} \times 40 \mathrm{~mm}$ area in the center of the composite bonded joint specimens [12]. 


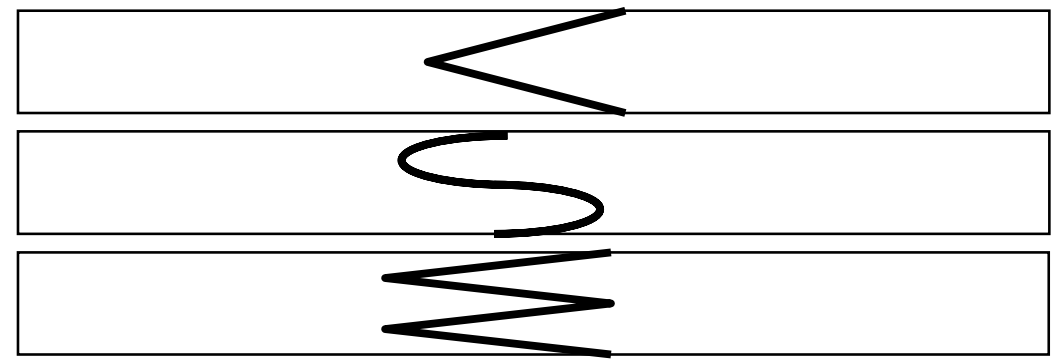

Fig. 1: Bond line configurations

\section{5- MODAL ANALYSIS USING FINITE ELEMENT METHOD}

A typical laminated composite bonded beam of dimensions $(350 \times 40 \times 5) \mathrm{mm}$ with various boundary conditions, Clamped-Clamped (C-C), Clamped-Simply Support (C-S), Simply Support-Simply Support (S-S) and Clamped-Free (C-F) along with the edges of beams are shown in the Fig. 2 . The figure shows the finite element model with three interconnected element. The element shown in Fig. 3 has three degrees of freedom at each node: translation in the nodal $X, Y$ directions and rotation about the nodal $Z$ axis. The stiffness matrix of the element can be then formulated as [13]:

$$
[K]=\mathrm{t}_{\mathrm{c}} \iint[B]^{\top}[D][B] d x d y
$$

where, $t_{c}$ is the thickness of composite beam, $[B]$ is strain matrix and [D]is the elasticity matrix of composite beam, which can computed as [14], for different code number, various degree of constraints at the medium ratio of fiber volume friction $\left(V_{f}\right.$ $=60 \%$ ). Here the equivalent flexural coefficient of the stiffness matrix of laminated layer is expressed as [15]:

$$
\mathrm{D}_{\mathrm{ij}}=\frac{1}{3} \sum_{k=0}^{n} \bar{Q}_{i j}\left(h_{k}^{3}-h_{k-1}^{3}\right)
$$

Where:-

$\mathrm{n}$ is the number of layers,

$\bar{Q}_{I J}$ is the transformed reduced stiffness,

$\mathrm{h}_{\mathrm{k}}$ is the thickness of the $k^{\text {th }}$ layer,

$\mathrm{i}, \mathrm{j}$ are indices varying from 1 to 3 .

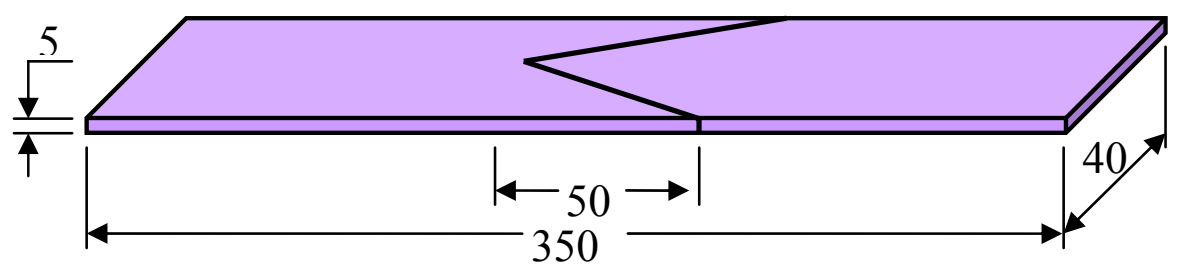

Fig. 2: Geometry of the bonded joint beam.

To represent the effect of stiffness for adhesive bonded joint on the stiffness matrix one can define the location of joint in the model as shown in Fig. 3. In the present 
model the longitudinal equivalent stiffness for bonded joint is represented by $\mathrm{K}_{\mathrm{L}}=$ $E A / L$, and the equivalent bending for bonded joint by $K_{b}=3 E I / L^{3}$, where $E$ is young modules of adhesive, L, A, I are the length, area and moment of inertia of bonded adhesive material respectively. The model of adhesive bonded joint is modeled and represented as shown in Fig. 4. The mechanical properties of adhesive bonded joint material are listed in Table 1. With the help of the mixture rule [16], the elastic module of $\mathrm{E}$ glass/polyester lamina are computed and listed in previous table.

Consequently the mass matrix of element can be formulated [13] as:

$$
[\mathrm{M}]=\rho_{c} \iint[\mathrm{N}]^{\top}[\mathrm{N}] \mathrm{dx} d \mathrm{y} .
$$

Where, $\rho_{c}$ is the density of composite beam with bonded joint; [N] is the matrix of shape function. Similarly, we can represent the effect of inertia for bonded joint in mass matrix by adding the mass of adhesive bonded layer $m_{b}$ for axial effect and mass moment of inertia $I_{b}$ for flexural effect. With the help of Eqs. 1, 2 and 3 the expanded forms of both element stiffness and mass matrices of the composite beam bonded joint are obtained in the matrix of order $(8 \times 8)$, Ref. [17]. For simplicity of the mathematical model the damping will not be considered.

The eigen-frequency can be then evaluated from the solution of the characteristic equation for composite beam bonded joint given by:

$$
[K]-\lambda[M][V]=[0]
$$

where $[V], \lambda$ are the eigenpairs

In view of Eqs. 4, the program has been coded into computer using Matlab (7.1) [18]. The program computes the eigenvalues and eigenvectors for five code numbers, three bounded line configurations and for four fixations namely C-C, C-S, S-S and C-F as shown in Table 3.
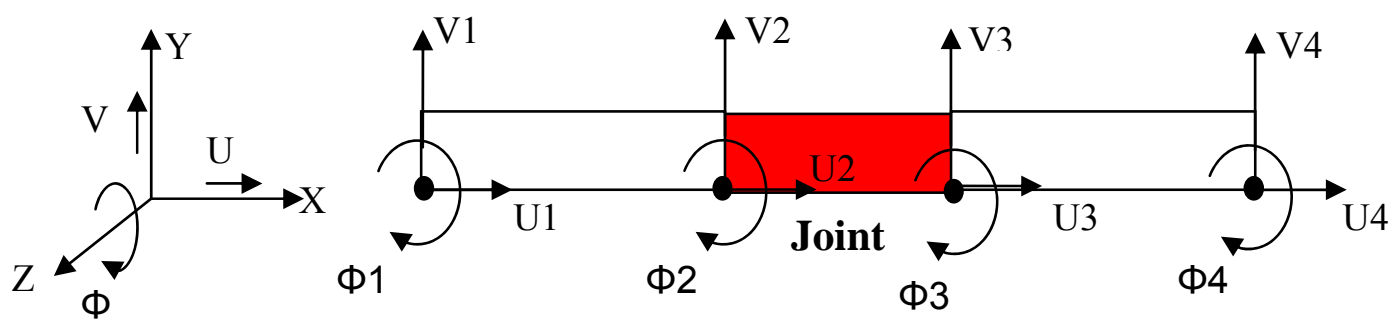

Fig. 3: Finite element model for bonded joint.

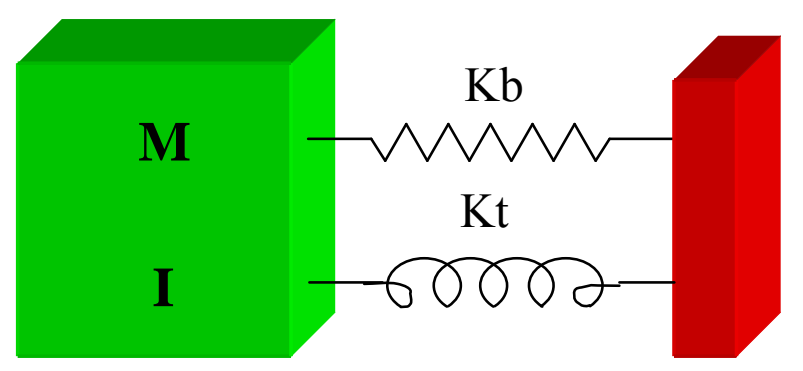




\section{6- EXPERIMENTAL WORK}

Fig. 4: Model of bonded joint.

\section{6-1- Ultrasonic Technique}

The magnetostractive pulse echo delay-line system [19] is utilized to measure the attenuation factor $\zeta$ and phase velocity $C_{p}$ investigations with slight modifications to allow the resonance frequency spectra for the longitudinal modes of these specimens to be obtained. In this modified system a general burst of mechanical oscillation is possible to excite the tested bonded composite along its main length at either the specific natural frequency or at one of the harmonic frequencies of the specimens. Fig. 5 shows the basic system used for these measurements while the recorded signal echo is schematically shown Fig. 6. The first part of the echo including the cross-over is the direct return of the transmitted signal, whilst the second part, the decrement, is the exponential retransmission of the energy stored. The number of oscillations to the cross over is a function of the line (wire) cross-section and the properties of resonating material. The parameters shown in this figure are utilized to calculate, absolutely, the attenuation factors according to [20]:

$$
\xi=\frac{20 \log \frac{A 1}{A 2}}{2 L}
$$

Where, $A_{1}$ and $A_{2}$ are the two consactive amplitude of wire and specimen respectively and also $L$ is the length of the wire and specimen. The longitudinal resonant modes of vibration of each tested composite bonded specimen were excited by cementing it with the remote end of the delay line (wire) of the system. The corresponding resonance frequencies were detected by measuring periodic time. For a specimen of length $L$, periodic time $t$, the phase velocity $C_{p}$ are related to this resonance frequency by [20].

$$
\mathrm{C}_{\mathrm{p}}=\frac{2 L}{t}
$$

The most accurate dynamic Young's modulus $\left(E_{d}\right)$ usually follows from determining ultrasonic $C_{p}$ be using the general relationship [20] given in equation (7). The measuring results of ultrasonic parameters are recorded and listed in Table 2.

$$
\mathrm{E}_{\mathrm{d}}=\rho \mathrm{C}_{\mathrm{p}}{ }^{2}
$$

where, $\rho$ is the denoted mass density.

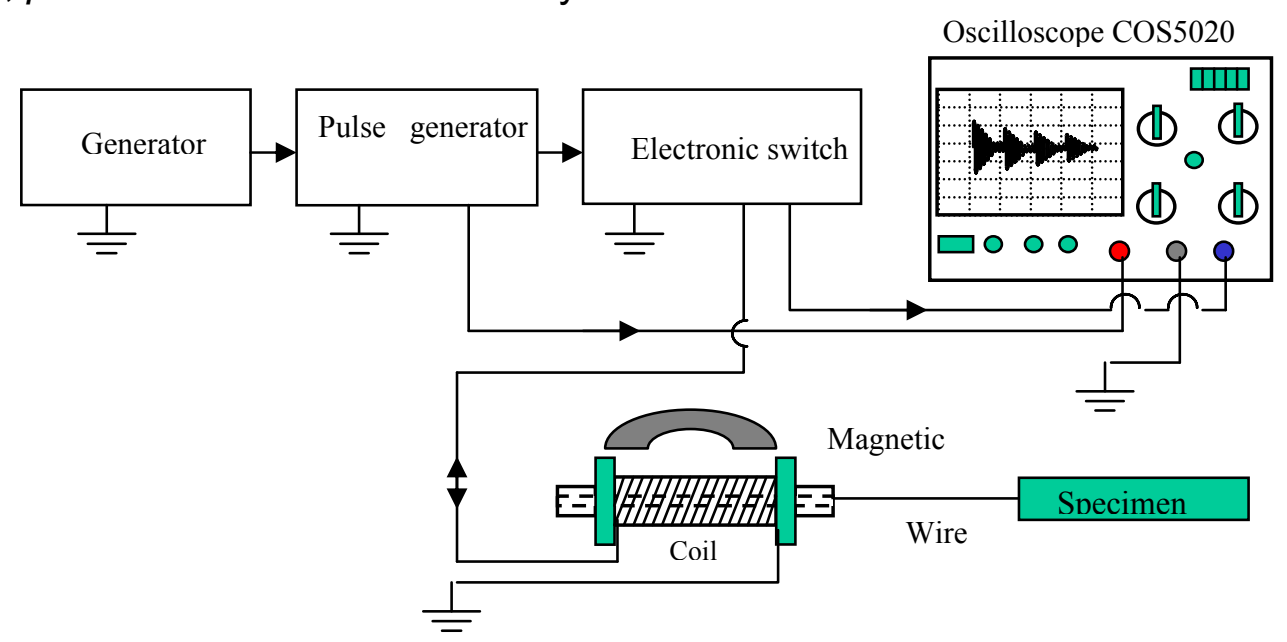


Fig. 5: Schematic diagram of the magnetostractive delay-line system.

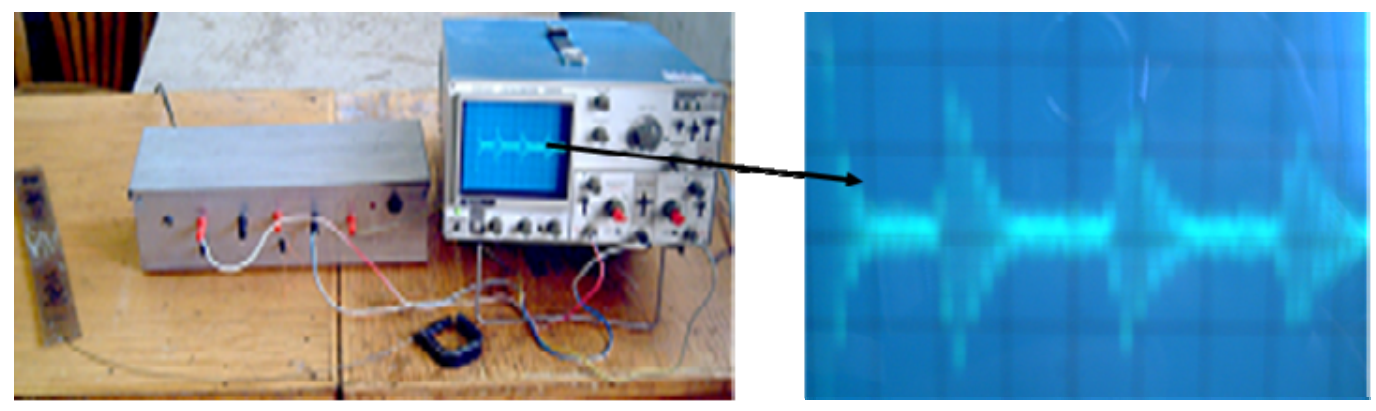

Fig. 6: Photographic and schematic diagram of the resultant echo-pattern displayed in the magnetostractive delay-line system.

\section{6-2 Ultrasonic Results}

The ultrasonic phase velocity propagation in the specimen $C_{p}$, the dynamic elastic modules $E_{d}$ and attenuated damping factor for the first two echoes are given in Table. 2.

It is clear that specimen with [0]5 orientations has higher $C_{p}$ and $E_{d}$ values compared with the other orientation. This is because the fibers are oriented in the same direction of wave propagation path. So the attenuation of the ultrasonic phase velocity was kept minimum. On the contrast damping values were lower for this type of orientation duo to the relative ease of energy transmission.

Regarding to bonded line configurations, Table 2 demonstrates that the $\mathrm{W}$-joint configuration has higher attenuation values compared with $\mathrm{V}$ - configuration. This is because relatively high adhesive content that will dissipate energy by various mechanisms. Several composite damping mechanisms were proposed and are briefly described as:

a- viscoelastic nature of matrix and/or fiber materials;

b- damping due to interface;

c- damping due to damage which includes frictional damping as a result of slip in unbound regions as well as damping due to dissipation in the area of matrix cracks;

d- viscoelastic damping at large amplitudes of vibration;

e- thermo elastic damping.

This explains the lower $\mathrm{Cp}$-values for the [0/90]5 compared with the other specimen $[0] 5$ by almost $34 \%$. Such attribution could explain the low $E_{d}-$ values for $[0 / 90] 5$ specimen compared with [0]5 specimen by almost $69 \%$.

Regarding the damping values, Table 4 shows that the specimen with bond configuration line [W] has high damping values compared with the [V] bond line type due to high dissipated energy.

The composite beam consists of fiber lamina within more layers and so can be considered as viscoelastic material, i.e. posses both elastic and viscous properties. Thus some of the energy stored in a viscoelastic system are recovered upon removal of the load. The remainder is dissipated by the material in the form of heat, resistance, so when the composite beam is subjected to ultrasonic energy, the fiber layer begins to slide resulting in a shearing action compared to matrix material. The 
pattern does more than just bond to the matrix. It also provides the mechanisms that create the damping effects as these shear strains are converted to heat energy within viscoelastic material. The dependence of damping values on fiber configuration is further observed from Table 2. From which the beam [0/90]5 has the higher attenuation values compared with the beam specimen [0]5.

It is observed that the obtained results for $E_{d}$ and $C_{p}$ are found to be symmetrical. In every composite specimen a maximum on the curve of $E_{d}$ is corresponding to a minimum in attenuation factor as shown in Fig. 9.

In addition, the fibers which are aligned at [0]5 with the direction of excitation are found to give the highest $C_{p}$ to the composite as shown in Fig. 10, simply because the fibers are aligned in the direction of the elastic sound waves and consequently are able to transmit their energy. Their propagation is limited with the resultant increase in dissipated energy and so attenuation factor $\zeta$.

\section{6-3- Frequency Response Function}

The experimental set up is shown in Fig.7. The specimen is located in a test rig and excited by an Impact hammer "type 8202". An ordinary hammer but has a force transducer type ' 8200 ' is built into its tip to register the force input. The hammer is used to excite the specimen at the anti node point. The charge amplifier type '2635' is used to generate the signal from the hammer to the dual channel analyzer type '2034' at A. The vibration response is registered by a suitable piezoelectric accelerometer (type '4374' its weight '2.4 grams'). The vibration meter (type 2511) is utilized in connection with the accelerometer to generate the signal to the dual channel analyzer (type 2034) at B. the frequency response spectrum can be obtained from the printer which is supported by the desktop computer series the dual channel analyzer[21]. Fig. 8 show the coherence and frequency response function recorded in a specimen [0]5 orientations at clamped-simple supported. The experimental measurements of the fundamental frequencies and damping parameters against different state of bond line configuration for the four types of boundary condition are listed in Table .4. The damping factor $\xi$ of a particular resonance can be calculated from the width of the resonance peak in magnitude of the (FRF) using half power method [22]. The values of the damping factor $\xi$ were plotted against various state of bond line configuration as shown in Fig. 12. 


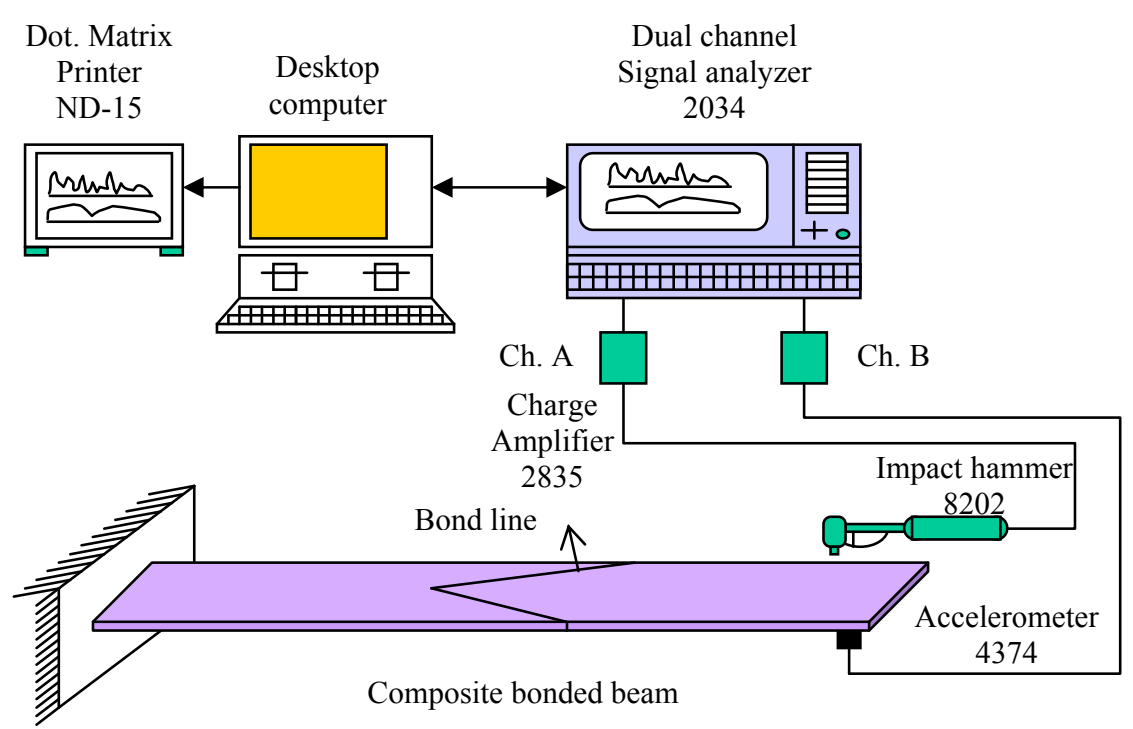

Fig.7: Instrumentation set-up formed from excitation and measuring systems.

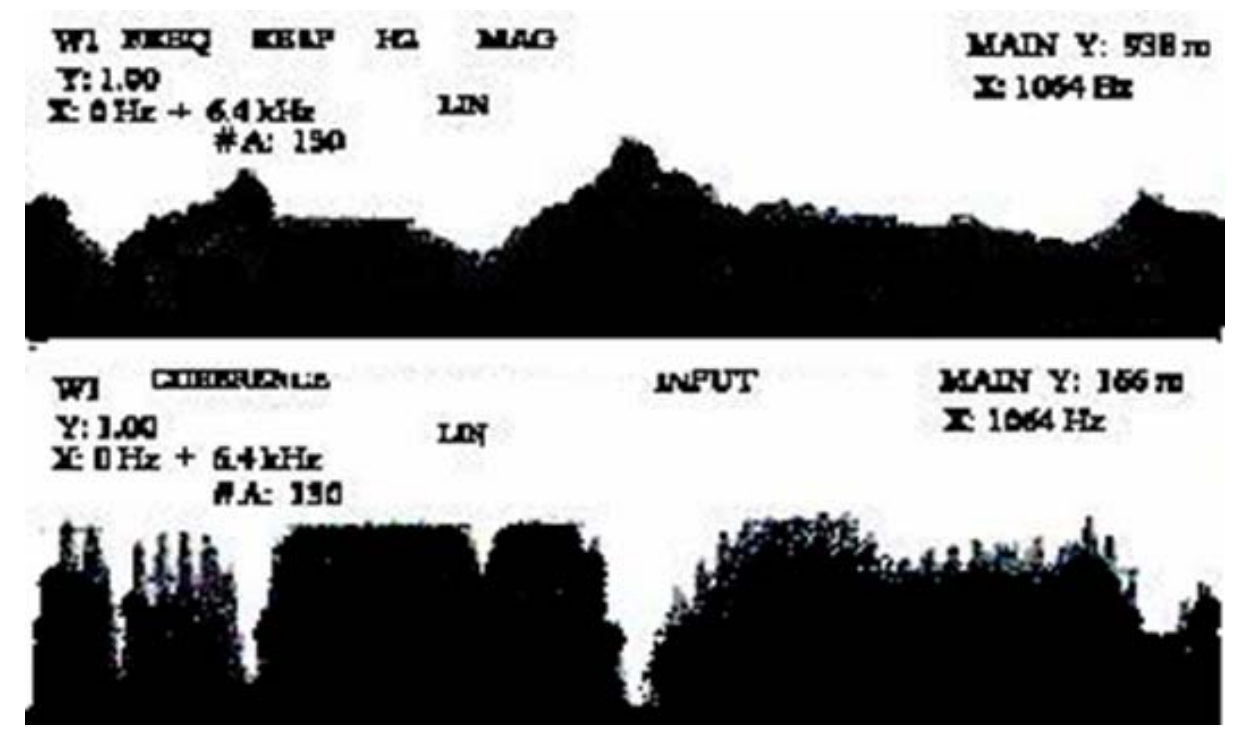

Fig. 8: A sample of frequency response function and coherence function for laminated bonded joint with [0] 5 orientations at clamped-simple supported.

\section{7- RESULTS AND DISCUSSIONS}

The resonance frequency of laminated composite beam with bonded joint dimension of $(350 \times 40 \times 5) \mathrm{mm}$ has been recorded with various bonded line configuration and analyzed for different fiber orientations and boundary fixations at the same five layers. As samples of the experimental results, the frequency response spectrums for laminated composite beam with orientation [0]5 at clamped-simple supported fixation is shown in Fig. 8. The measured and the computed fundamental frequencies are shown in Table 2. The experimental results verified the numerical values, obtained from the solution of Eq. 4. The numerical results of the present paper have been found to be in a good conformity with the experimental results. From Fig.11, it can be observed that specimen [0/90/0/90/0] has the lowest frequency compared with the 
other specimen while the specimen [0]5 has the highest values this is due to the minimum and maximum values of flexural elastic modules and stiffness at this orientation respectively. In view of different fixation, the rate of change of the eigenfrequencies via different fixations are relatively high compared with the rate of change due to the use of the various code numbers of fiber orientations as shown in Fig.11 and Table3. On the other hand from Fig. 12. the damping factor increasing monotonically as the angle of bond line configuration increasing reached maximum at the bond line joint $(\mathrm{W})$ this is due to maximum dissipated energy in this adhesive joint type. These variations depend mainly on the magnitude of acute angles between the lamina orientation and direction of bond line configuration. This means that the life time in a typical bond joint may be increased by increasing the acute angles these results can easily investigated by comparing the bond line joint $\mathrm{V}, \mathrm{S}$ and $W$ Thus the eigen-parameter may be controlled by changing the fiber orientations the bond line joint and boundary fixations. Consequently the obtained results provide an useful tool for the designer to select the proper fiber orientation and boundary fixation to shift the natural frequencies as desired, particularly in the resonance zones.

In the presence of bonded joint for laminated composite beam experimental measurements have been carried out to verify that the developed finite element model of composite assembly.

\section{8- CONCLUSIONS}

The dynamic analysis of laminated composite beam with different fiber orientations, bonded line configuration and boundary fixations are investigated analytically and experimentally. From the numerical and experimental results one can conclude:

1-The present comparison between the numerical and experimental results proves that the suggested finite element models of the composite structural beams with bonded joints provide an efficient tool for the dynamic analysis with proper accuracy.

2- The damping capacity is always inversely proportional to the stiffness of the bonded joint specimens. The rate of the proportionality depends mainly on the bond line configuration type, lamina orientation, and boundary conditions. This in turn provides the analysis with an efficient tool for accurate evaluation for selecting the proper criteria of the specimens for controlling the presented damping capacity and the proper resistance against deformation during the operating process.

3-The avoidance of rapid failure of the composite structures with bonded joint due to the shear effect (particularly at the resonant modes) can be attained by selecting the proper bond line configuration type for example the composite beam with bond line type [W] and lamina orientation [0/45]5 is more convenient .

4- The present study provides an efficient non-destructive technique for the predication of dynamic properties for an adhesive bonded joint for the studied composite structure systems.

\section{REFERENCES}

[1] A. Kaya, M. S. Tekelioglu, F. Findik, "Effects of various parameters on dynamic characteristics in adhesively bonded joints", Journal of Materials Letters Vol. 58, pp 3451-3456, 2004.

[2] S. He, M.D. Rao, "Vibration analysis of adhesively bonded lap joint" Part 1, 2. Theory, Journal of Sound and Vibration Vol.152, pp 405-412, 1990. 
[3] S. He, M.D. Rao, "Longitudinal vibration and damping analysis of adhesively bonded double-strap joints", ASME Journal of Vibration and Acoustics Vol. 114, pp 330- 342, 1992.

[4] S. Roy, N. Reddy, "Finite element models of viscoelasticity and diffusion in adhesively bonded joints", International Journal for Numerical Methods in Engineering Vol. 26, pp 2531-25, 1988.

[5] A.A. Khalil, A.N. Kagho, "Non-destructive testing of adhesively bonded joints using vibrational analysis", International Journal of Adhesion and Adhesives Vol.11, (2), pp 121-129, 1991

[6] A. Kaya, "Investigation of stress distributions in adhesive-bonded lap joint", MS Degree Thesis, Dokuz Eylul University, Institute of Science and Technology, December, I'zmir, 1991.

[7] Y.P. Shi, S. Cheng, "Analysis of adhesive-bonded cylindrical lap joints subjected to the axial load", Journal of Engineering Mechanics Vol. 119, (3), pp 584-592, 1993.

[8] M.D. Rao, H. Zhou, "Vibration and damping of a bonded tubular lap joint", Journal of Sound and Vibration Vol. 178, (5), pp 577-590, 1994.

[9] K.C. Shin, Y.G. Kim, D.G. Lee, J.M. Chai, "Adhesively bonded lap joints for the composite-steel shell structure of high-speed vehicles", Composite Structures Vol. 38 (1-4), pp 215-233, 1997.

[10] A. Vaziri, H.N. Hashemi, "Dynamic response of tubular joints with an annular void subjected to a harmonic axial load", International Journal of Adhesion and Adhesives Vol. 22, pp 367-375, 2002.

[11] V. Tita, J .de Carvalho, J. Lirani, "Theoretical and experimental dynamic analysis of fiber reinforced composite beams", J. of the Braz. Soc. Mech. Sci. 7 Eng. XXV, Vol. 3, pp 306-310, 2003.

[12] Z. Kristin, L. Dahsin, "Geometrical parameters in composite repair", Journal of Composite Materials, Vol. 29, (11), pp 1473-1480, 1995.

[13] O. C. Zienkiewicz, Taylor, "The finite element method", 4 thedn, Mcgraw. Hill, New York, 1989.

[14] R. Chandra, S. Singh, K. Gupta, "A study of damping in fiber-reinforced composites", Journal of Sound and Vibration, Vol. 262, pp 475-496, 2003.

[15] R. M. Jones," Mechanics of composite materials", Scripta Book Company, 1975.

[16] A. A. Hamada, "An investigation into the eigen-nature of cracked composite beams", Journal of Composite Structures, Vol. 38,pp 45-53, 1997.

[17] A. Maher, EL-Soaly, S. Ghoneam, A. Hamada, "Eigen-analysis of fiber reinforced composite plates", Journal of Composite Structure, Vol. 28, pp 521529, 1993.

[18] M. R. Hatch, "Vibration simulation using matlab and ansys" Chapman and Hall/CRC, 2001.

[19] A. H. Khafagy, "Acoutical and mechanical investigation on metallic and dielectric solid media", ph. D Thesis, university of London, 1985.

[20] V. Rajendran, A. V. Gayathri Devi, M.Azooz, F. H. El-Batal, "Physicochemical studies of phosphate based $\mathrm{P}_{2} \mathrm{O}_{5}-\mathrm{Na}_{2} \mathrm{O}-\mathrm{CaO}-\mathrm{TiO}_{2}$ glasses for biomedical applications", journal of Non-Crystalline Solids Vol. 353, pp 77-84, 2007.

[21] A. A. Hamada, "Vibration and damping analysis of beams with composite coats", Journal of Composite Structure, Vol. 32, pp 33-38, 1995. 
[22] A. Maher and A. Hamada, "Dynamic analysis of laminated composite structure with bolted joints", 8th International conference on production engineering and control, PEDAC, 2004.

Table 1: Mechanical properties of the adherent and adhesive materials.

\begin{tabular}{|l|c|c|c|c|}
\hline \multicolumn{1}{|c|}{ Materials } & $\mathrm{E}[\mathrm{GPa}]$ & $\mathrm{G}[\mathrm{GPa}]$ & $\rho \mathrm{g} / \mathrm{cm}^{3}$ & $\mathrm{v}$ \\
\hline E-glass & 72.4 & 4.0 & 2.539 & 0.2 \\
\hline Polyester & 3.5 & 2.0 & 1.2 & 0.35 \\
\hline Adhesive 2015 & 1.98 & 0.42 & 1.1 & 0.32 \\
\hline
\end{tabular}

Table 2: Ultrasonic measurements.

\begin{tabular}{|c|c|c|c|c|}
\hline \multicolumn{2}{|c|}{$\begin{array}{l}\text { Code number\& Bonded } \\
\text { joint configurations }\end{array}$} & \multirow{2}{*}{$\begin{array}{c}\zeta \\
0.00480 \\
0.00560 \\
0.00609\end{array}$} & \multirow{2}{*}{$\begin{array}{c}\mathrm{Cp},(\mathrm{m} / \mathrm{sec}) \\
4500.5 \\
4403.0 \\
4200.1\end{array}$} & \multirow{2}{*}{$\begin{array}{c}E_{d}, G P a \\
25.66 \\
24.54 \\
22.33\end{array}$} \\
\hline [0/0/0/0/0] & $\begin{array}{l}\mathrm{V} \\
\mathrm{S} \\
\mathrm{W}\end{array}$ & & & \\
\hline$[0 / 30 / 0 / 30 / 0]$ & \begin{tabular}{|l}
$\mathrm{V}$ \\
$\mathrm{S}$ \\
$\mathrm{W}$
\end{tabular} & $\begin{array}{l}0.00620 \\
0.00681 \\
0.00709\end{array}$ & $\begin{array}{l}4153.4 \\
4063.2 \\
3961.7\end{array}$ & $\begin{array}{l}22.15 \\
21.20 \\
20.12\end{array}$ \\
\hline$[0 / 45 / 0 / 45 / 0]$ & $\begin{array}{l}\mathrm{V} \\
\mathrm{S} \\
\mathrm{W}\end{array}$ & $\begin{array}{l}0.00721 \\
0.00753 \\
0.00789\end{array}$ & $\begin{array}{l}3832.3 \\
3743.6 \\
3596.0\end{array}$ & $\begin{array}{l}19.21 \\
18.33 \\
16.93\end{array}$ \\
\hline [0/60/0/60/0] & \begin{tabular}{|l} 
V \\
S \\
W
\end{tabular} & $\begin{array}{l}0.00810 \\
0.00840 \\
0.00894\end{array}$ & $\begin{array}{l}3534.0 \\
3403.9 \\
3352.6\end{array}$ & $\begin{array}{l}16.35 \\
15.40 \\
14.70\end{array}$ \\
\hline [0/90/0/90/0] & \begin{tabular}{|l} 
V \\
S \\
W
\end{tabular} & $\begin{array}{l}0.00910 \\
0.00991 \\
0.01100\end{array}$ & $\begin{array}{l}3340.7 \\
3293.3 \\
3142.4\end{array}$ & $\begin{array}{l}15.20 \\
14.15 \\
12.88\end{array}$ \\
\hline
\end{tabular}

Table 3: Values of fundamental frequency in $\mathrm{Hz}$ for various laminated codes, different boundary fixation and bound line configurations (Finite element \& Experimental results). 


\begin{tabular}{|c|c|c|c|c|c|c|c|c|c|}
\hline $\begin{array}{c}\text { Boundary fixations, } \\
\text { Orientations \& } \\
\text { Configuration }\end{array}$ & \multicolumn{2}{|c|}{ C- C } & \multicolumn{2}{c|}{ C - S } & \multicolumn{2}{c|}{ S - S } & \multicolumn{2}{c|}{ C - F } \\
\cline { 3 - 10 } & & F.E. & Ex. & F.E. & Ex. & F.E. & Ex. & F.E. & Ex. \\
\hline \multirow{2}{*}[0/0/0/0/0]{} & V & 82.4 & 79 & 57.5 & 56 & 32 & 30 & 15.9 & 16 \\
& $\mathrm{~S}$ & 81.8 & 77 & 55 & 49 & 30.4 & 26 & 14.1 & 14 \\
& $\mathrm{~W}$ & 80 & 76 & 51.6 & 43 & 28.4 & 21 & 12.3 & 12 \\
\hline \multirow{3}{*}[0/30/0/30/0]{} & $\mathrm{V}$ & 79.9 & 78 & 55.1 & 53 & 30.1 & 26 & 14.2 & 14 \\
& $\mathrm{~S}$ & 78.3 & 76 & 52.4 & 46 & 28.3 & 22 & 13.1 & 12 \\
& $\mathrm{~W}$ & 76.7 & 74 & 48.9 & 42 & 26.1 & 19 & 11.7 & 10 \\
\hline \multirow{3}{*}[045/0/45/0]{} & $\mathrm{V}$ & 77.7 & 75 & 53.3 & 51 & 27.6 & 21 & 13.2 & 13 \\
& $\mathrm{~S}$ & 75.1 & 73 & 49.2 & 44 & 25.1 & 18 & 12.1 & 12 \\
& $\mathrm{~W}$ & 73.4 & 70 & 46.3 & 39 & 22.8 & 16 & 10.9 & 10 \\
\hline \multirow{3}{*}[0/60/0/60/0]{} & $\mathrm{V}$ & 76.2 & 73 & 52.3 & 47 & 25.3 & 19 & 11.8 & 12 \\
& $\mathrm{~S}$ & 73.2 & 71 & 48 & 42 & 23.5 & 16 & 10.2 & 11 \\
& $\mathrm{~W}$ & 70.1 & 68 & 45. & 37 & 20.8 & 15 & 9.1 & 10 \\
\hline \multirow{2}{*}[0/90/0/90/0]{} & $\mathrm{V}$ & 74.3 & 70 & 47.6 & 41 & 22.4 & 18 & 11 & 11 \\
& $\mathrm{~S}$ & 71.5 & 67 & 45.2 & 39 & 20.1 & 15 & 9.7 & 10 \\
& $\mathrm{~W}$ & 67 & 65 & 43.7 & 34 & 17.5 & 14 & 8.3 & 8 \\
\hline
\end{tabular}

${ }^{*} \mathrm{C}=$ clamped, $\mathrm{S}=$ simple - supported $\& \mathrm{~F}=$ free

Table 4: Values of fundamental frequency and damping factor for various laminated codes, different boundary fixation and bound line configurations (Experimental results).

\begin{tabular}{|c|c|c|c|c|c|c|c|c|c|}
\hline \multirow{2}{*}{\multicolumn{2}{|c|}{$\begin{array}{c}\text { Boundary } \\
\text { fixations, } \\
\text { Orientations \& } \\
\text { Configuration }\end{array}$}} & \multicolumn{2}{|c|}{$C-C$} & \multicolumn{2}{|c|}{$C-S$} & \multicolumn{2}{|c|}{$S-S$} & \multicolumn{2}{|c|}{$C-F$} \\
\hline & & \multirow{2}{*}{$\begin{array}{c}\text { Freq } \\
. \\
79\end{array}$} & \multirow{2}{*}{$\begin{array}{l}\text { Damp. } \\
0.061\end{array}$} & \multirow{2}{*}{$\begin{array}{c}\text { Freq } \\
56\end{array}$} & \multirow{2}{*}{$\begin{array}{l}\text { Damp. } \\
0.091\end{array}$} & \multirow{2}{*}{$\begin{array}{c}\text { Freq } \\
. \\
30\end{array}$} & \multirow{2}{*}{$\begin{array}{l}\text { Damp. } \\
0.135\end{array}$} & \multirow{2}{*}{$\begin{array}{c}\text { Freq } \\
. \\
16\end{array}$} & \multirow{2}{*}{$\begin{array}{l}\text { Damp. } \\
0.165\end{array}$} \\
\hline & V & & & & & & & & \\
\hline [0/0/0/0/0] & $S$ & 77 & 0.095 & 49 & 0.114 & 26 & 0.140 & 14 & 0.170 \\
\hline & W & 76 & 0.112 & 43 & 0.136 & 21 & 0.146 & 12 & 0.176 \\
\hline \multirow{3}{*}[0/30/0/30/0]{} & $\mathrm{V}$ & 78 & 0.105 & 53 & 0.121 & 26 & 0.155 & 14 & 0.186 \\
\hline & $S$ & 76 & 0.127 & 46 & 0.143 & 22 & 0.159 & 12 & 0.192 \\
\hline & W & 74 & 0.144 & 42 & 0.156 & 19 & 0.164 & 10 & 0.196 \\
\hline \multirow{3}{*}[045/0/45/0]{} & $\mathrm{V}$ & 75 & 0.134 & 51 & 0.164 & 21 & 0.188 & 13 & 0.232 \\
\hline & $S$ & 73 & 0.156 & 44 & 0.183 & 18 & 0.219 & 12 & 0.296 \\
\hline & W & 70 & 0.197 & 39 & 0.227 & 16 & 0.246 & 10 & 0.347 \\
\hline \multirow{3}{*}[0/60/0/60/0]{} & $\mathrm{V}$ & 73 & 0.169 & 47 & 0.197 & 19 & 0.237 & 12 & 0.291 \\
\hline & $S$ & 71 & 0.199 & 42 & 0.235 & 16 & 0.273 & 11 & 0.365 \\
\hline & W & 68 & 0.227 & 37 & 0.294 & 15 & 0.322 & 10 & 0.403 \\
\hline \multirow{3}{*}{ [0/90/0/90/0] } & $\mathrm{V}$ & 70 & 0.196 & 41 & 0.231 & 18 & 0.291 & 11 & 0.348 \\
\hline & $\mathrm{S}$ & 67 & 0.243 & 39 & 0.292 & 15 & 0.314 & 10 & 0.425 \\
\hline & W & 65 & 0.287 & 34 & 0.331 & 14 & 0.363 & 8 & 0.478 \\
\hline
\end{tabular}




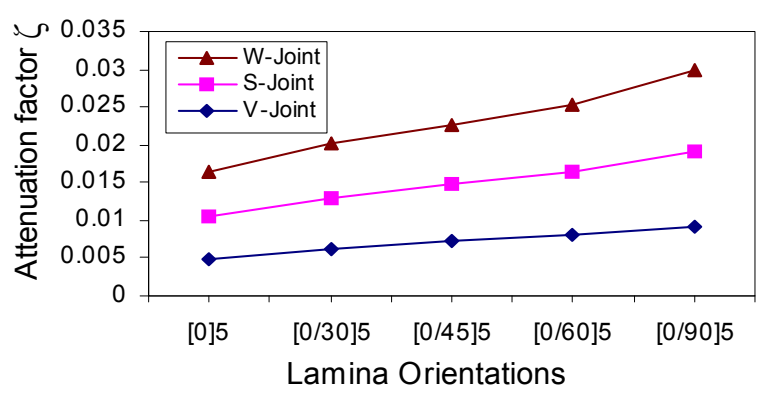

Fig. 9: Effect of lamina orientations on attenuation factor at different bond line configurations and boundary fixations.
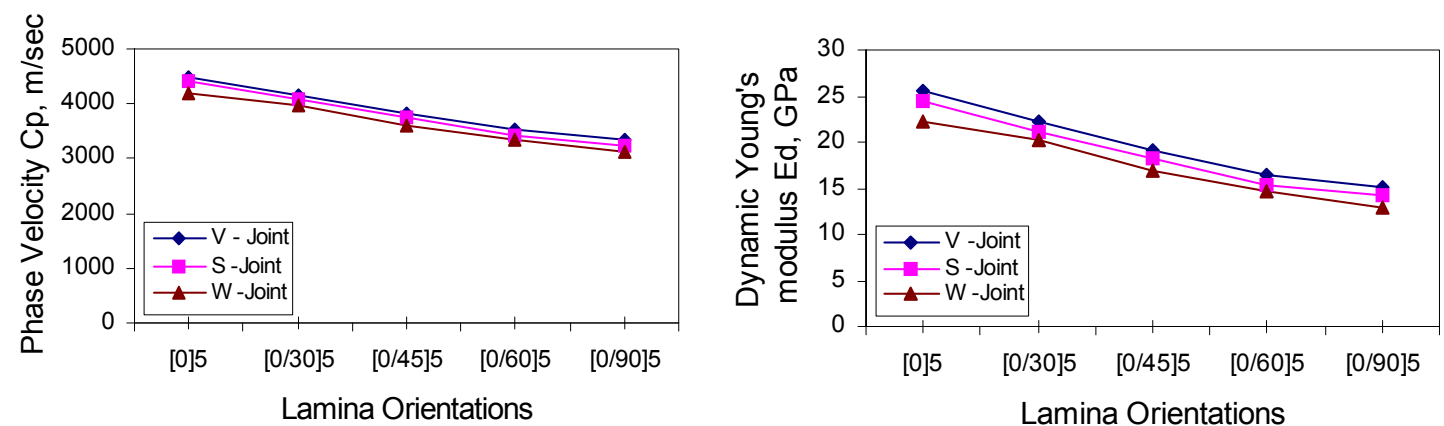

Fig. 10: Effect of lamina orientations on dynamic Young's modulus and sound velocity at different bond line configurations and boundary fixations.
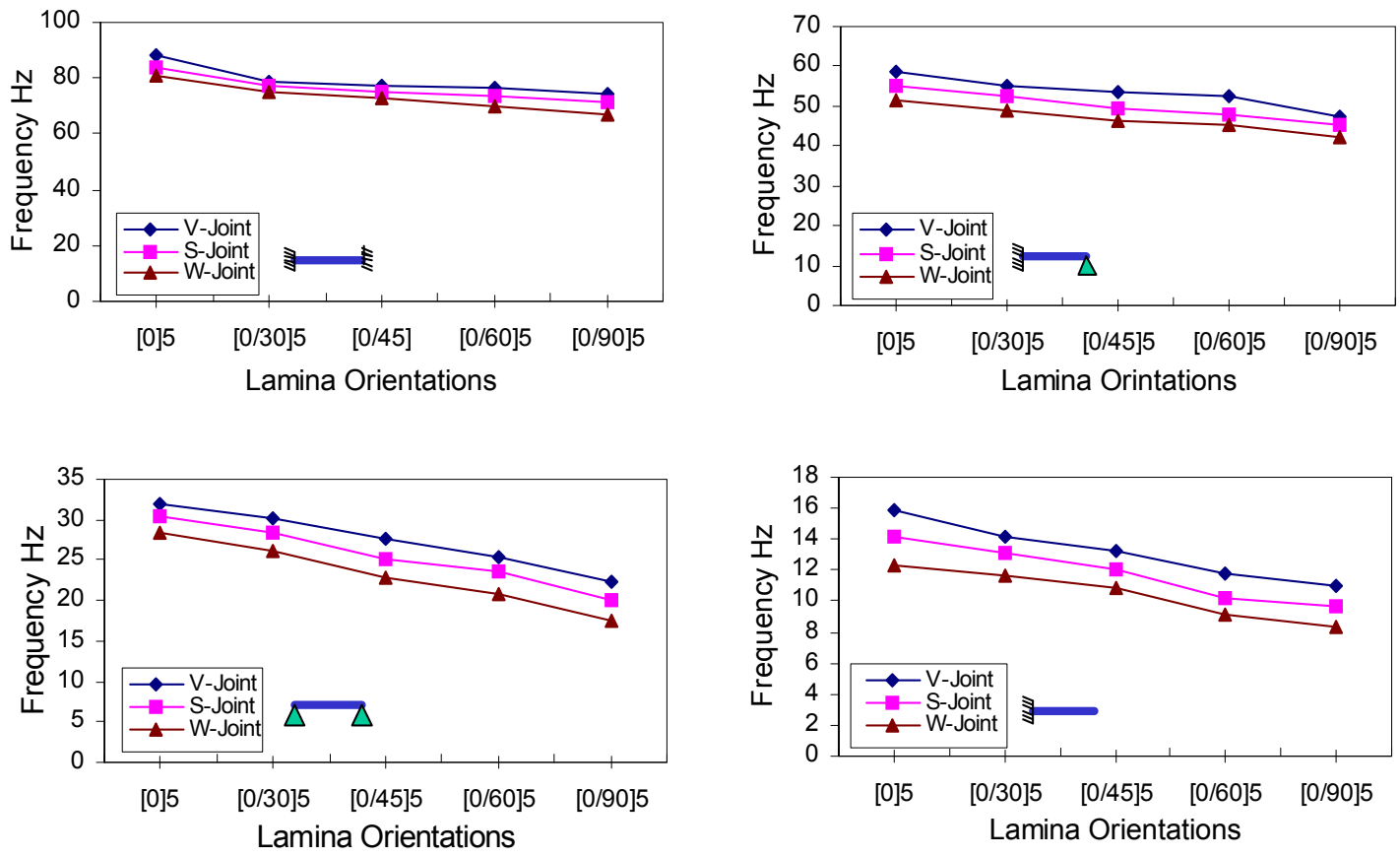

Fig. 11: Effect of lamina orientations on frequency at different bond line configurations and boundary fixations (numerical results). 

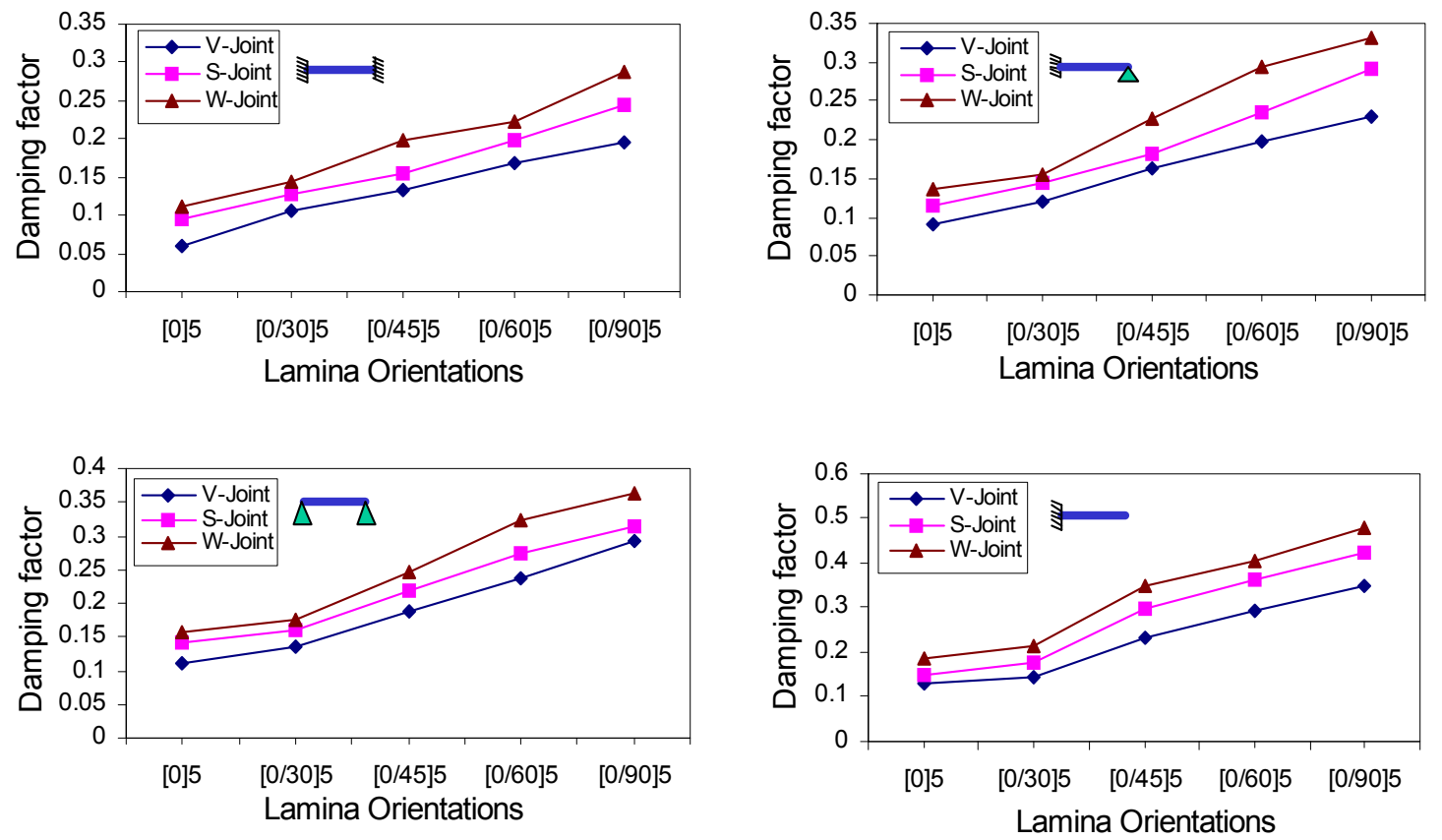

Fig. 12: Effect of lamina orientations on damping factor at different bond line configurations and boundary fixations 